\title{
AC 2008-2543: ENHANCING ENGINEERING EDUCATIONAL OUTCOMES THROUGH INTEGRATION OF NEW VISION FOR CIVIL INFRASTRUCTURES WITH NANOTECHNOLOGY INTO UNDERGRADUATE CURRICULUM AND ITS IMPLEMENTATION RESULTS
}

\section{Wei Zheng, Jackson State University}

Dr. Wei Zheng currently serves as an Assistant Professor of Civil Engineering at Jackson State University. He received his Ph.D. degree in Civil Engineering from University of

Wisconsin-Madison in 2001. He is a registered Professional Engineer in Wisconsin and has over10-year industrial experience.

\section{HuiRu Shih, Jackson State University}

Dr. HuiRu (H.R.) Shih is a Professor of Technology at Jackson State University (JSU). He received his Ph.D. degree in Mechanical Engineering from the University of Missouri. Dr. Shih is a registered professional engineer in Mississippi and a member of the American Society of Mechanical Engineers (ASME).

\section{Karen Lozano, University of Texas-Pan American}

Dr. Lozano currently serves as an Associate Professor of Mechanical Engineering at the University of Texas-Pan American. She received her Ph.D. degree in Materials Science from Rice University in 1999. Her research interests include nano-reinforced systems for engineering applications.

\section{Karl Kiefer, Invocon, Inc., Houston, Taxes}

Mr. Kiefer currently serves as President \& CEO of Invocon, Inc., Houston, Taxes. He obtained Master's degree in electrical engineering and has over 20-year experience in development of wireless sensor and its data processing. He is an active advocator for integration of wireless sensor technology into undergraduate curriculum.

\section{Xinqing Ma, Inframat Corp, Farmington, Connecticut.}

Dr. Ma currently serves as Vice-President of Industrial NanoCoatings in Inframat Corp, Farmington, Connecticut. He has over 10-year experience in research and development of nanostructured materials research and product for infrastructures. 


\title{
Enhancing Engineering Educational Outcomes through Integration of New Vision for Civil Infrastructures with Nanotechnology into Undergraduate Curriculum and Its Implementation Results
}

\begin{abstract}
Nanotechnology enables the creation and utilization of materials and devices with novel functions through the control of matter at the nanoscale level. It can be expected that the nanotechnology has the potential to revolutionize the design and construction of civil infrastructures. Nevertheless, the excitement and promise of nanotechnology for conceiving innovative systems can provide a new opportunity for educational institutions to stimulate interest and broaden the vision of diverse students in engineering and research, foster active learning and life-long learning, and inspire innovation and creativity. The objective of this paper is to share strategies for utilizing nanotechnology as a vehicle to strengthen engineering curriculum and enhance undergraduate engineering educational outcomes. The paper presents instructional strategies and new course modules for integrating nanotechnology education into a mainstream civil engineering undergraduate curriculum. The outcomes from the first year implementation are revealed, and their implications and future improvement are discussed.
\end{abstract}

\section{Introduction}

Nanotechnology enables the development of miniature sensors and smart materials with higher performance and multi-function (e.g. self-healing, sensing and actuating). The nation's best thinkers on nanotechnology and transportation gathered at a recent workshop and envisioned the advances that could be made possible through nanotechnology in the future ${ }^{1}$ : cracked bridges and pavement repair on their own, guardrails re-align automatically after impact, bridges adjust their shapes to control movement caused by winds, coatings make metal structures self clean to avoid corrosion, and make road sign never need to be washed, rearranging and combining alloy particles could make bridge steel many times more durable and stronger, miniature sensors could be embedded into highways or coat an entire bridge for monitoring the processes of deterioration, and allowing to fix them long before they are apparent to human inspectors.

Researches are now carried out towards the use of nanotechnology in design, construction, monitoring, and control of civil infrastructures ${ }^{2-6}$, meanwhile a fewer of nanotechnology or its analogy is already being used in construction. For example, the addition of nanoscale silica fume has been recognized as a big improvement in durability of concrete structures exposed to de-icing salts and sea water, which chemicals could penetrate concrete's porous structure and cause deterioration to the structure. Even though the current cost of nanotechnology-enabled materials and devices may hinder their widespread application for civil infrastructures, their price will be expected to drop and the benefits from their application could justify the additional cost in the near future. It can be expected that the nanotechnology has potential to revolutionize the design and construction of civil infrastructures. To ensure future workforces to possess the skills and knowledge that can make them adaptable to the dynamic changes in transcendent technology, there is an imperative need to introduce specific nanotechnology application into civil engineering curriculum in a timely and suitable manner ${ }^{7}$. 
Nevertheless, the excitement and promise of nanotechnology for conceiving innovative systems can provide a new opportunity for educational institutions to stimulate interest and broaden vision of diverse students in engineering and research, foster active learning and life-long learning, and inspire innovation and creativity. The innovations of nanotechnology typically exemplify strategies for creativity or innovative problem-solving, including Innovation through Synthesis, in which one combines different materials or functions to create novel materials or functions; and Creativity through Transformation, in which one begins with an already existing object or idea, and searches for ways it can be altered to provide possible solutions to a new problem. These innovations can add a new dimension in traditional civil engineering and its curricula, and particularly provide civil engineering students with intellectual stimulation and inspiration for innovative problem-solving and creativity, which the traditional civil engineering undergraduate curricula lack.

For example, a research was conducted for developing a nanotechnology-based device, which can be mixed with and embedded in concrete and combine signal processing with a wide variety of measurements of pressure, temperature, chemical, stress, strain, and offer promise for the advancement of both nondestructive evaluation and condition-based maintenance of structures ${ }^{8}$. Through mimicking the micro/nano scale lotus leaf surface, self-clearing paint has been developed to repel water and dirt on the surface and benefits traffic sign and building façade by limiting periodic clearning 9 . Inspired from biological system, a self-healing polymeric composite material was developed by incorporating embedded microcapsules containing healing agent and a catalytic chemical trigger. An approaching crack ruptures microcapsules and results in releasing healing agent and a catalytic chemical trigger into the cracks and bonding the crack faces ${ }^{10}$. A similar self-healing approach would be applied into concrete, in which micro-sized hollow fibers filled with crack sealant would be introduced. If the concrete cracked, the fibers would also break and release sealant. Another self-healing mechanism for concrete is to have high fraction of anhydrous (lacking water) cementitious material, which is left after the reaction with the water in the initial concrete mix and could be a reservoir for further hydration. When a micro-crack develops, fresh anhydrous surfaces are exposed. If the concrete is soaked with water, hydration starts again, and the newly forming hydrates can rapidly fill and seal cracks ${ }^{11}$.

Based on the above rationale, authors had proposed an educational project for integrating nanotechnology for civil infrastructures into engineering undergraduate curriculum through multi-disciplinary collaborations among educational institutions and industries. The paradigm development mainly focuses on enhancing undergraduate engineering educational outcomes specified by ABET and fostering innovative problem-solving skills exemplified by nanotechnology. The proposed project was implemented in 2007 under the support from Nanotechnology Undergraduate Education Program in National Science Foundation.

\section{Strategies for Integration of Nanotechnology into Civil Engineering Curriculum}

The objectives for integrating nanotechnology for civil engineering into the existing curriculum are: (1) to introduce the application and cutting-edge research developments of nanotechnology in civil engineering for undergraduate students; (2) to update traditional mainstream civil engineering curricula; and (3) to develop new teaching strategies and diverse learning 
opportunities to strengthen civil engineering curriculum and enhance engineering educational outcomes. Among mainstream civil engineering curricula, the course Construction Materials and Lab deals with the properties of construction materials, as well as standardized testing procedures, measurement and data acquisition, and includes both lecture and laboratory sessions. It is an ideal venue for adopting the new developments of nanotechnology in civil engineering.

The key element in instructional strategies is to fully utilize the excitement and innovation brought forward by nanotechnology to create diverse learning opportunities for stimulating interest and broadening vision of students in engineering and research, fostering active learning and life-long learning, and inspiring innovation and creativity. The proposed diverse learning activities and expected outcomes are essentially aligned with these ABET-specified engineering educational outcomes and shown below in the conceptual model of the new course modules (see Fig.1).

New Course Module Activities

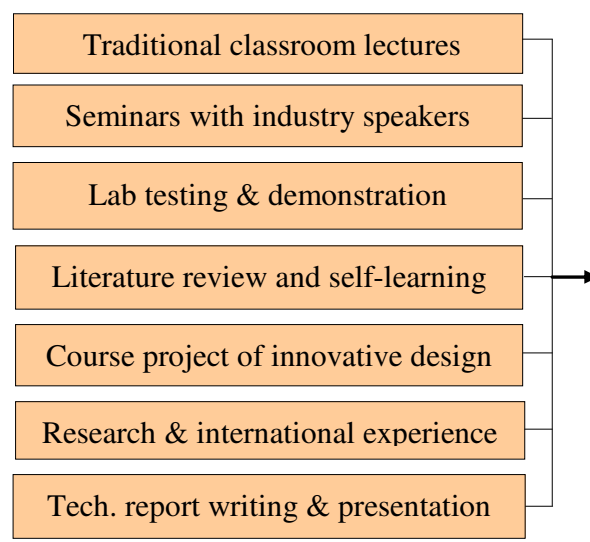

Short-Term Educational Outcomes

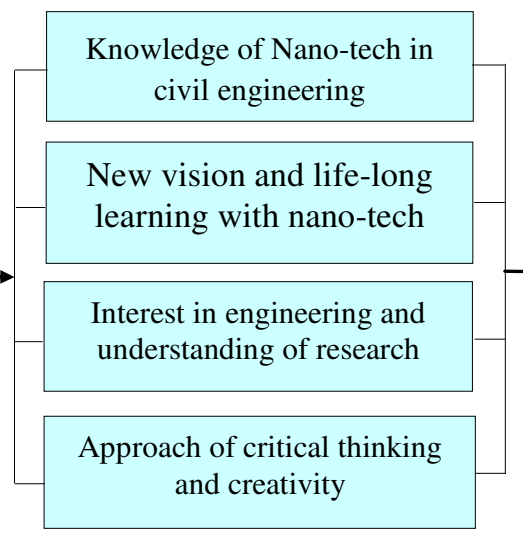

\section{Long-Term Broad Outcomes}

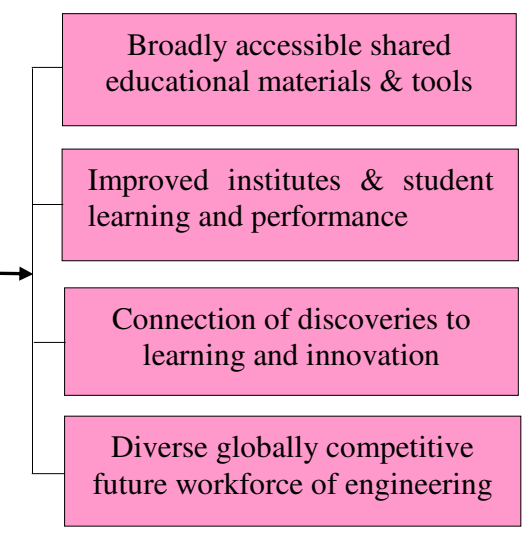

Fig.1Conceptual Model of the New Course Module: Learning Activities and Expected Outcomes

The instructional strategies will encompass general concept development and creativity with nanotechnology to convey the new vision for civil engineering to students, and impart fundamental knowledge that students will need to work with the nanotechnology in civil engineering in the future. While the themes center on the nanotechnology for civil engineering, some proposed course and lab modules include currently available smart materials, e.g. Shape Memory Alloys (SMAs) and Piezoelectric (PZT) materials, and micro/nano-scale technologies, e.g. silicon fume and micro-fiber modified concrete and MEMS (Micro-Electro-Mechanical Systems) sensors, and concrete maturity method, due to availability of applicable technology and operational feasibility at the current civil engineering teaching laboratory. Even though these technologies may not constitute real nanotechnology, they do demonstrate analogies of how nanotechnology will impact students' careers and civil infrastructures in the future, and inspire students' desire for creativity and innovation. Furthermore, these technologies have been applied in civil engineering practice. Inclusion of these topics will update engineering curriculum and fill the gap between the engineering curriculum and current practice.

New Course Module Framework and Student Leaning Activities 
New course modules are partitioned into four aspects: (a) improved construction materials; (b) sensing technology and wireless sensors; (c) multi-functional materials and smart infrastructure; and (d) innovative design. They have been developed and integrated into existing curriculum seamlessly, including four lecture modules, four lab modules, and two seminars by industry guest speakers. Diverse student learning activities focus on active learning through the course design project, along with self-learning, literature searching and reviewing, hands-on lab activities, and research experience.

Lecture Module 1: Introduction of Techniques for Creativity and Assignment of Course Project - Design of Innovative Infrastructures through Nanotechnology

In this module, the course design project - Innovative Design of Civil Infrastructure and its requirements are assigned to students at the beginning, and followed by presentation of strategies for creativity and innovation. The objective of course design project is to provide a platform for students to engage in the active learning on innovation and nanotechnology throughout the course module implementation, practice strategies for innovation and apply the knowledge of nanotechnology presented in the subsequent new course modules, explore their potential for Innovation and creativity, and experience fun and enjoyment from creativity. It requires that students apply nanotechnology-enabled multiple-functional materials and devices, or combination of them, to innovatively solve existing problems in civil engineering and design novel infrastructures. Students are free to choose any subject related to their field for the project. The project report is also required to include technical writing, graphic illustration of design, and describe how the design utilizes nanotechnology and how the ideas for problem-solving and creativity are proceeded. These ideas of design and solution in the project were exchanged through post presentations among students from the project participating universities.

Following the project assessment, one of the classic models of creativity - the Wallis Model of the Creative Process ${ }^{12}$ - was presented to students. This model describes four-stage process which people use to approach problems and come up with creative solutions, which include:

- Preparation: One defines the problem, need, or desire, and gathers any information on the solution or responses that need to be encompassed, and then sets up criteria for verifying the solution's acceptability;

- Incubation: One steps back from the problem and lets his or her minds contemplate and work it through;

- Illumination: Ideas arise from the mind to provide the basis of a creative response. These ideas can be pieces of the whole or the whole itself, e.g. the entire concept or entity at once;

- Verification: One carries out activities to demonstrate whether or not what emerged in illumination satisfies the need and the criteria defined in the preparation stage.

The reference to Disney's creative cycle and other strategies for creativity and innovation ${ }^{13-15}$ were also given to students in this module.

It is expected that the strategies for creativity and subsequent new course modules could help students foster the origination of new ideas and obtain inspiration for their design project. As the course proceeds, students are presented with new course modules on nanotechnology and its development for civil engineering and instructed to review the course materials and references, 
which are developed by authors and contain samples of innovations and applications of nanotechnology for civil engineering. Students are also encouraged do their own search and literature review for the information they need for their course projects and communicate with instructors for more information and advice.

Lecture Module 2: Behaviors of Material and Manufacturing at the Nanoscale

This module is intended to provide students with basic understanding of behavior of materials and manufacturing at the nanoscale. It was developed and presented to students based on the parts of the course module framework developed and implemented for the course Principles of Materials by Froyd et al. at Texas A\&M University under NSF support. This includes two basic ideas underling differences at the nanoscale: scaling and granularity, and two different approaches to nanoscale manufacturing: top-down (use existing techniques to fabricate smaller and smaller features) and bottom-up (start with atoms or molecules and assemble larger units).

\section{Lecture Module 3: Nanotechnology Development for Civil Engineering}

The objective of the module is to introduce the future vision of civil engineering with nanotechnology, to reveal the excitement and creativity of new development of nanotechnology in civil engineering, and to inspire students' creativity and emphasize the importance of life-long learning. This module was introduced through slide presentation and companied with physical sample demonstration, such as MEMS sensors and self-cleaning paint (see Fig.2). It is intended to give students brainstorm of nanotechnology development and reveal how the new technology will impact their careers and civil infrastructures in the future.

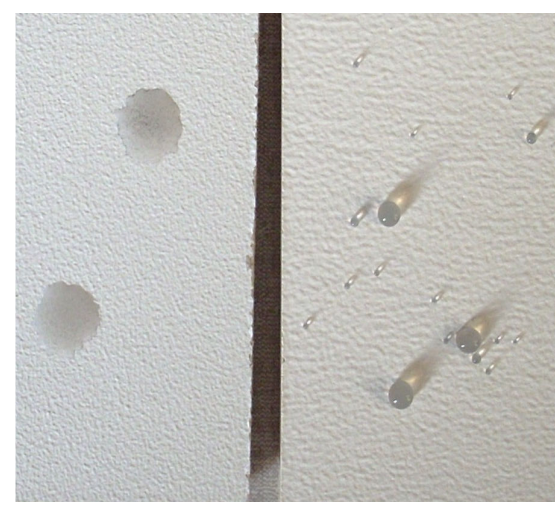

Fig.2 Self-clearing paint vs. normal paint

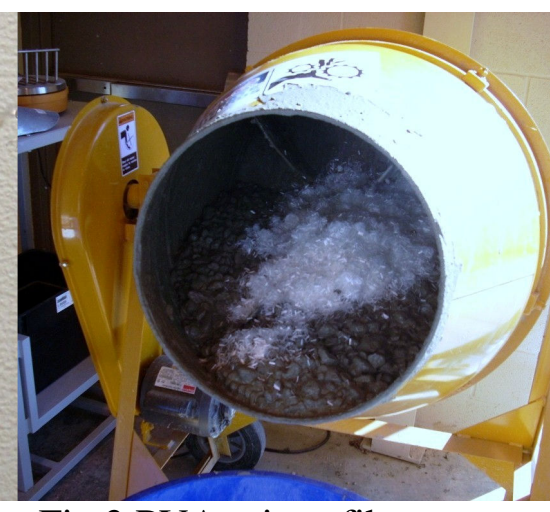

Fig.3 PVA micro-fibers are mixed with concrete

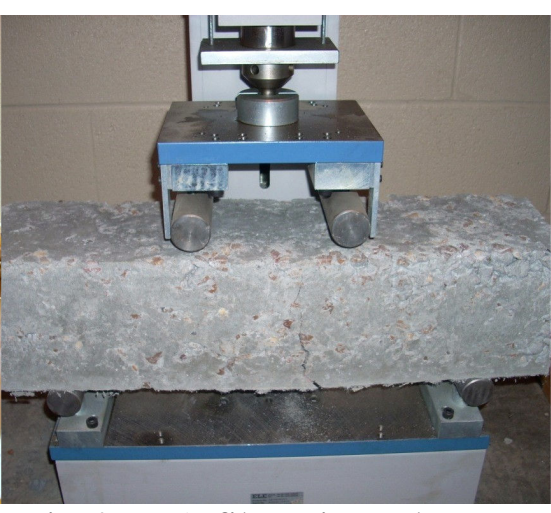

Fig.4 PVA fibers impede crack in flexural specimen

Lecture Module 4: Properties of Smart Materials and Nano/Micro-Scale Modified Concrete

The objective of this module is to provide students with the fundamental understanding that the properties of materials can be changed through different arrangement of their nanoscale structure, and to provide background information for hands-on laboratory activities. While addressing the unique properties of two smart materials: Shape Memory Alloys (SMAs) and Piezoelectric (PZT) materials, it is also intended to give students a general sense on what nanotechnology can achieve by producing similar or advanced smart multi-functionally adaptive 
materials through nanocomposite-by-design. This topic on nano/micro-scale modified concrete emphasizes that concrete is composed of porosities arranging from air voids to nano-scale pores. This results in a brittle material that is much stronger in compression than in tension. Nanoscale particles, such as silica fume ${ }^{16}$, can interact with different concrete-making materials and fill and reduce nanoscale pores. Micro/nano-diameter fibers, such as the polyvinyl alcohol (PVA) structural-fiber ${ }^{17}$ and Carbon nanotubes, can produce tougher cement-based products and a higher modulus of elasticity than normal concrete when the fibers has strong bond at the nanoscale with cement matrix. All these modifications on concrete have potential to improve concrete mechanical properties by impeding cracking formation and growth, which initiate from the nanoscale pores.

\section{Lab Module 1: Nanoscale Silica Fume Modified and Micro-Fiber Reinforced Concrete}

The objective of this modulus is to demonstrate how the properties of bulk materials can be manipulated and improved through changing the material micro/nano scale structure. This demonstration is accomplished through modification of traditional student laboratory hands-on activities in the existing curriculum. In the traditional curriculum, students are divided into several groups to design normal concrete mix with different strength, cast concrete specimens, test and measure the modulus of elasticity, compressive and flexural strength of the concrete in standard procedures. The new lab module modifies the traditional lab activities by replacing the normal concrete in two student groups with silica fume modified concrete and micro-diameter fiber reinforced concrete respectively. The silica fume modified concrete is proportioned by adding silica fume SF-20 ${ }^{16}$ with the weight of 5-10\% of the required cement in the concrete mix. Based on a dosage of 20-40 pounds per cubic yard of the concrete mix, the polyvinyl alcohol (PVA) structural-fiber ${ }^{17}$ is added to the normal concrete to make micro-fiber reinforced concrete (see Fig.3 and Fig.4). All students are able to compare the results of the different tests and see how the modifications affect the concrete's performance.

\section{Lab Module 2: Determine Concrete Maturity Index Using Miniature Embedded Sensor}

This module will provide students with hands-on experience on Concrete Maturity Method $(\mathrm{CMM}){ }^{18}$ by using MEMS temperature sensors. CMM is developed to estimate the concrete strength through correlating the concrete strength with concrete maturity index (e.g. temperaturetime index) that is produced and measured during concrete hydration process. This method can be used to estimate the strength of concrete and speed construction by removing forms and loading the concrete early. Since the cost of temperature sensors embedded in concrete has been reduced, this makes the CMM attractive to construction industries. However, this topic has not been covered in the current curriculum. In this new lab module, a miniature temperature sensor, iButton ${ }^{19}$ (see Fig.5), was embedded into concrete specimens during students cast concrete specimen in Lab Module 1 (see Fig.6). The temperature during the concrete curing process was recorded by iButton. After the concrete specimen was broken through compression tests, iButton sensors were taken out (see Fig.7) and connected to a computer to load recorded temperaturetime data to computer (see Fig.8). The correlation between the concrete strength and its maturity index can be established. Then, the strength of concrete in construction sites can be estimated through the concrete maturity index measured through embedded temperature sensors and the well-established correlation between the concrete strength and its maturity index. 


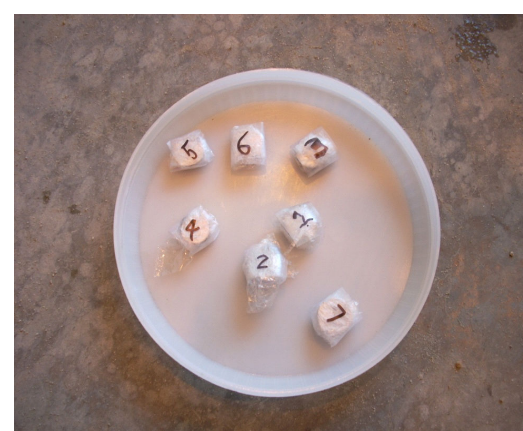

Fig.5 iButton sensors ready for embedding in concrete

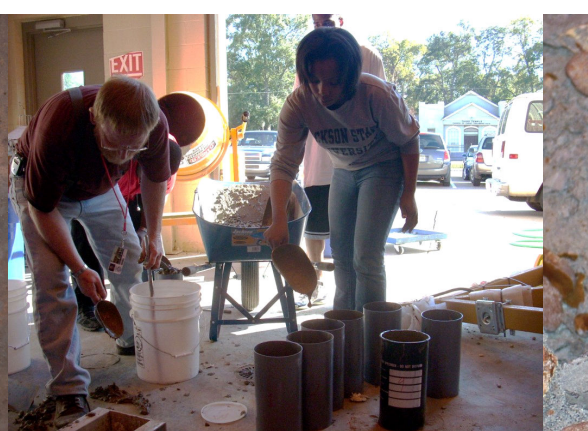

Fig.6 Students cast concrete specimen and embed iButton

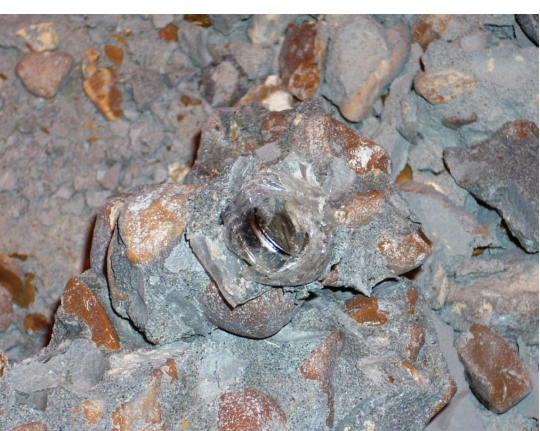

Fig.7 iButton is taken from concrete after test

Lab Module 3: Unique Properties of Shape Memory Alloys (SMAs)

In traditional lab activities, the standard tensile test of carbon steel is usually conducted to reveal its strain-stress relation by using MTS testing machine. The objective of this new lab module is to use the same test setting to exhibit SMAs' super-elastic effect and shape memory effect. When loaded to a certain level, the specimen of Austenite phase SMAs displays behaviors similar to yielding (e.g. deformation without increasing its resistance). Its unloading path in the stress and strain plot differs from the original loading path, but the SMAs recover its original shape once the load is removed. This is super-elastic behavior of SMA and enables SAMs to possess better energy dissipation capacity that is suitable for vibration control and improving seismic performance of building. The specimen of Martensite phase SMAs possesses a residual deformation after the certain load is applied and then totally removed. However, the residual deformation in the specimen can totally disappear and specimen recovers its original shape after heating it over the Austenite finish temperature. This demonstrates the shape memory capacity of SMAs. Alternatively, the wires of Austenite phase SMAs ${ }^{20}$ (see Fig.9) can be used for student lab activities. These Austenite-phase SMAs wires were pre-stretched with a permanent deformation and can contract into its original length through heating provided by elastic current going through the SMAs wires, and can be used as actuator under the given electric current and acts as muscle in smart/intelligent structures.

\section{Lab Module 4: Unique Properties of Piezoelectric Material}

This modulus demonstrates the properties of Piezoelectric (PZT) materials that are commonly used to make sensors and actuators and reveal the basic principle of intelligent structure or structure control through a built-up instrument ${ }^{21,22}$. The instrument is made of a cantilever beam to which the piezoelectric patches are attached as both a sensor and an actuator (see Fig.10). When the cantilever beam deflects, the piezoelectric patch will send out signal. If the deflection remains unchanged, then the signal disappears. However, once the cantilever beam is forced to vibrate, the piezoelectric material can continue sending out signals. Once the circuit to the actuator patch is on, the receiving signals are processed by a computer algorithm, and then the computer sends signals to activate the actuator to suppress the vibration of the cantilever. 


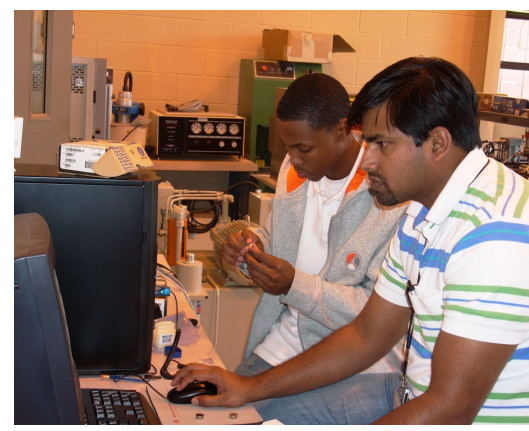

Fig.8 Download the data from iButton to the computer

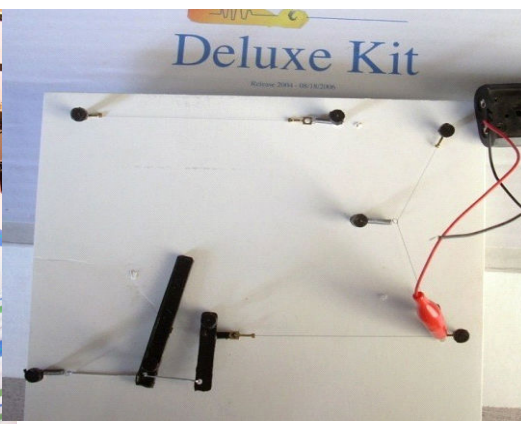

Fig.9 Deluxe Kit for shape memory effect of SMAs

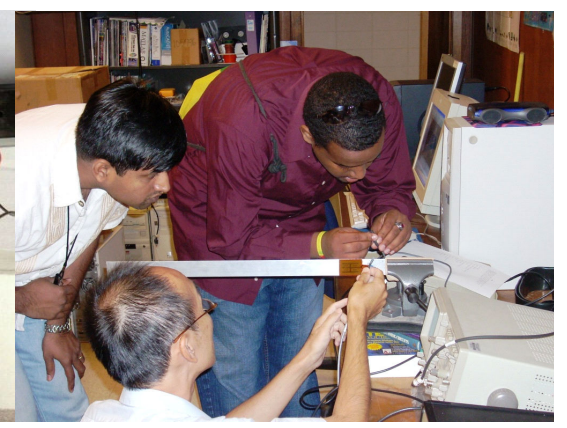

Fig.10 Smart cantilever beam with piezoelectric patches

\section{Seminars from Industry Perspectives by Industrial Guest Speakers}

Seminar 1-Nanocoating for Infrastructure and Its Manufacturing was provided on-campus, including nanocoating manufacturing and research development, and overview of nanocoating techniques available for infrastructures, and their application examples and further development. Seminar 2-Wireless Sensor and Its Data Processing in Practical Application covered wireless sensor data processing for practical applications, including the demonstration of basic principles of wireless sensor system through the demonstration instruments, identification of a fake signal, and filtering the noise to obtain true signal from wireless sensors.

\section{Outcomes from the $1^{\text {st }}$ Year Implementation}

New course modules were implemented in the course Construction Materials and Lab for the first time in 2007. The students' learning outcomes on innovation and creativity can be evaluated based on the course design projects. Early assignment of the design project allowed students have more time to engage in active learning throughout the new module implementation, get involved in making their efforts for examining current problems for civil infrastructures, initiate their own innovative design through searching literature and self-learning, and communicate with instructors about their ideas. Even though students' projects may be far away from realization under the current technology, the project development did allow student experience the process of innovative-thinking and creativity, which did not typically occur in the traditional civil engineering curriculum.

Twenty-three design projects have been developed by students and presented in the format of poster. It is the authors' assessment that there are four projects that really grip some original and innovative ideas, such as the concepts of Ideal Aggregates for Concrete (IAC) and Textile Reinforced Concrete (TRC) (see Fig. 11). Although the majority of the projects may not evidently demonstrate that innovative concepts or solutions were originated by students, students did search literatures for research development, and perceived and presented the innovations related to nanotechnology to innovatively solve the civil engineering problems. In the future implementation, it will be emphasized that the students should clarify what their innovations in the project are, and how the innovations are developed and built on others' previous work, as well as reference and credits to others' previous work should be given in the presentation. The majority of students was excited about and enjoyed doing this course project and presenting their innovative design. Positive comments on the project experience and the introduction of 
innovation strategies from students included: "I think this gave the students a chance to think outside the box and allowed each person to be free"; "Include practical applications to aid creativity"; and "My knowledge about it is unknown; we need to brush-up on it."

\section{Innovative Ideal Aggregates for Concrete}

Ideal Aggregates for Concrete (IAC) was innovatively proposed by a student team in their course final project. Through nanotechnology, IAC surface be formed with indentions and peaks to maximize the friction and interlocking of the particles, and surface coating will be added to improve the bond of Interfacial Transition Zone between IAC and the hydrated gel. The grid of lasers will cut the aggregate to the perfect shape and well-graded size. This will improve concrete strength and control concrete production quality.

\section{Textile Reinforced Concrete}

Textile Reinforced Concrete (TRC) was presented in students' course final project. A textile made through nanotechnology are stitchbonded multi-plies that can have different orientations. The textile fibers also contain hollow capillaries that contain a bonding agent. When the cracks rupture fibers and release the bonding agent which rebinds the concrete crack. The textile would improve both strength and the durability of the concrete.

Fig.11 Samples of Course Final Project- Design of Innovative Civil Infrastructures

After each new module was introduced, a brief questionnaire was also given to students to allow them to provide feedback and comments. Students were asked to give a score based on a 1 to 5 scale to evaluate the interesting aspect and practical aspect, as well organization, presentation, and the in-depth of the content of each modules topic. Available preliminary results from one university $(\mathrm{N}=12)$ are shown in Table 1 below.

Table 1 Results from evaluation of implementation of new course module topics

\begin{tabular}{|c|c|c|c|c|c|c|}
\hline \multirow{2}{*}{\multicolumn{2}{|c|}{ Modules Topics }} & \multicolumn{5}{|c|}{ Evaluation score on characteristics of new module topics * } \\
\hline & & Interesting & Practical & Organization & Presentation & In-depth \\
\hline 1. & Innovative Design and creativity & 2.64 & 2.91 & 3.45 & 2.93 & 3.09 \\
\hline 2. & Materials and manufacturing at Nanoscale & 3.27 & 3.36 & 3.18 & 3.18 & 3.55 \\
\hline 3. & Nanotechnology in civil Engineering & 3.82 & 3.82 & 3.36 & 3.73 & 3.73 \\
\hline 4. & Smart materials and application & 3.60 & 3.60 & 3.10 & 3.10 & 2.90 \\
\hline $5 a$. & Silica fume modified concrete & 3.00 & 3.73 & 3.18 & 3.45 & 3.18 \\
\hline $5 \mathrm{~b}$. & Micro-fiber reinforced concrete & 4.00 & 4.09 & 3.64 & 3.45 & 3.25 \\
\hline 6. & Concrete Maturity Method & 3.36 & 3.82 & 3.09 & 3.09 & 3.45 \\
\hline 7. & Shape Method Alloys & 3.60 & 3.60 & 3.00 & 2.60 & 2.70 \\
\hline 8. & MEMS Sensors & 3.17 & 3.50 & 2.83 & 3.00 & 2.83 \\
\hline 9. & Nanocoating for infrastructures & 3.80 & 3.70 & 3.10 & 2.80 & 3.00 \\
\hline 10. & Wireless sensor and data processing & 3.08 & 3.85 & 2.85 & 3.15 & 2.85 \\
\hline \multicolumn{2}{|r|}{ Average Score for All Modules } & 3.39 & 3.63 & 3.16 & 3.14 & 3.14 \\
\hline \multicolumn{2}{|c|}{ Overall Average Score for Modules } & \multicolumn{5}{|c|}{3.29} \\
\hline
\end{tabular}

Note: Rates are on a 1 to 5 scale to indicate the relative importance or extent of various factors in ascending order.

For all new course modules, the average rate of students' interest is 3.39/5.0, while the average score in the practical aspect is 3.69/5.0. This indicates that students think module topics in general are between "interesting" and "very interesting", and are between "practical" and "very practical", based on the rating scale. These results signify that the proposed project did stimulate students' interest at and desire for learning nanotechnology-related topics. Students perceived the new course module topics with more appreciation in practical aspect than in interesting aspect. The average score for all modules in each aspect is above 3.0/5, indicating that students are 
generally satisfied with the in-depth of content, organization, and presentation of these modules. Authors try to identify the reason for some aspect for individual module with an average rate below 3.0 and will improve them for the future implementation.

The lowest ranked module in both the interesting and practical aspects is the Innovative Design and Creativity Strategies with 2.63/5.0 from the interesting aspect and 2.91/5.0 from the practical aspect. Further examination on survey data reveals that $50 \%$ of students rated this topic "interesting" and $8.3 \%$ of students rated it "very interesting", while $50 \%$ of students rated the module "practical" and $16.6 \%$ of students thought it "very practical". This indicates the majority of students think this topic is interesting and practical. However, $8.3 \%$ of students rated this topic as "not interesting all"; $24.9 \%$ of students rated it "interesting to a little extent" and "practical to a little extent". It is the authors' assessment that these students who rated the topic with lower score may be not interested at research or invention, and may also not realize the strategies and practice for creativity introduced in this module could also be used for routine problem-solving. The future implementation of this module will emphasize that the linkage between Innovative Design and Creativity Strategies and routine problem-solving skill, and evaluate if this linkage can improve students' perception of this module in both interesting and practical aspects.

Students' positive comments on the short survey for the new course modules included: "Enjoyed learning nanotechnology. It is a wave of the future, and I will be using this hopefully in my career"; "Would like to see related workshops or internship"; "Helped to understand more of what's going on with concrete"; "Worth learning"; "Would like to learn more"; "Timely"; and "Very informing". Some suggestions from students included: "I believe that this can be better put together if we have an outline to go by. I want to know what types of projects possible in the course. I really like how creative I can make myself on this project"; "The topic is very new, and I am not yet able to suggest pertinent material - perhaps some more background in what nanotechnology is and how nano-science is being viewed; direction etc."; "Would like to learn more"; "More specific examples needed"; and "Need at least one lecture on this to show application using MATLAB or any other program." Negative comments from some students include: "Vague, more information needed"; "More electrical engineering, and was a little hard to follow"; "Very confusing"; and "Too much time spent on this".

It is the instructor's assessment that these students who have the above negative responses might not recognize that tacking the challenge in civil engineering needs interdisciplinary approaches, and just felt that there were too much new subjects to learn in the course Construction Materials. The authors will examine students' study and assignment on lab report, self learning and course design project and balance existing course contents and new modules. Authors will add more specific application examples and refine the course modules in the future implementation. Furthermore, the authors will explore new strategies to elevate students' learning interest and motivate them to take more challenge and efforts in their studies.

Overall evaluation of the implementation was also conducted to measure students' change in knowledge and attitude through pre- and post- questionnaires at the beginning and the end of the implementation. A short version of questions in the questionnaire is presented in Table 2. Students were asked to give a rate based on a 1 to 5 scale to indicate the relative extent or importance of various factors in ascending order. Rates from the pre-test questionnaire from 
three universities are shown in Table 2. The pre-test results indicate that the students from three universities showed a similar trend in their attitude towards most questions before the implementation of new course modules: higher rate in their interest at engineering and pursuing an engineering career, and excitement at learning engineering; lower rate in their knowledge on nanotechnology and its application, as well as their leaning related knowledge and technology from previous courses; and medium rate in their pre-knowledge about methodology and strategies of innovation and creativity, and their willingness to pursue graduate study.

Table 2 Short Version of Questions in Questionnaire and Rates* from Pre-Test Questionnaire

\begin{tabular}{|c|c|c|c|c|}
\hline \multirow{2}{*}{\multicolumn{2}{|c|}{ Questions (in abbreviation) }} & \multicolumn{3}{|c|}{ Pre-Test Score } \\
\hline & & $\mathrm{UO}^{\mathrm{a}}$ & $\mathrm{JSU}^{\mathrm{b}}$ & UTPA $^{\mathrm{c}}$ \\
\hline Q1 & Interested in engineering & 4.54 & 4.89 & 4.78 \\
\hline Q2 & Excited to study engineering & 4.46 & 4.67 & 4.63 \\
\hline Q3 & Pursue an engineering career & 4.77 & 4.78 & 4.67 \\
\hline Q4 & Interested in engineering research & 2.85 & 4.44 & 4.00 \\
\hline Q5 & Pursue graduate study for Master's degree & 3.38 & 4.50 & 3.89 \\
\hline Q6 & Pursue graduate study for Ph.D. & 1.77 & 2.78 & 2.96 \\
\hline Q7 & Pursue an engineering research career in future & 2.38 & 3.78 & 3.44 \\
\hline Q8 & Known about nanotechnology & 2.23 & 2.67 & 2.48 \\
\hline Q9 & Learned about nanotechnology in previous courses & 2.08 & 2.78 & 1.59 \\
\hline Q10 & Relate nanotechnology to civil engineering & 2.36 & 2.67 & 2.00 \\
\hline Q11 & Perceive nanotechnology will impact civil engineering & 3.08 & 4.00 & 4.11 \\
\hline Q12 & Know about strategies of innovation and creativity & 2.92 & 3.22 & 3.37 \\
\hline Q13 & Learnt about strategies on creativity in previous courses & 3.00 & 2.67 & 3.04 \\
\hline Q14 & Utilized the strategies on creativity to conduct any activities before & 3.54 & 3.67 & 3.11 \\
\hline Q15 & Know about the future vision for civil engineering & 3.23 & 3.67 & 2.44 \\
\hline Q16 & Knowledge of Pace in which new technology will develop in civil engineering & 3.46 & 4.44 & 3.74 \\
\hline Q17 & Know engineering and research development abroad & 2.62 & 3.44 & 2.74 \\
\hline Q18 & Chance to know engineering and research abroad & 2.54 & 3.78 & 2.74 \\
\hline Q19 & Chance to know people and their culture abroad & 3.23 & 3.89 & 2.96 \\
\hline Q20 & Think that lifelong learning is important & 4.00 & 4.89 & 3.96 \\
\hline
\end{tabular}

Note: * Rates are based on 1 to 5 scales to indicate the relative importance or extent of various factors in ascending order; a- University of Oklahoma; b-Jackson State University; c- University of Texas- Pan American

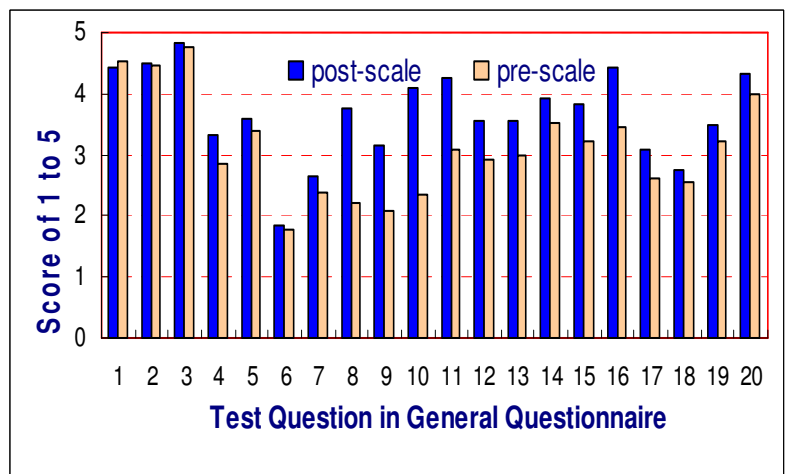

(a)

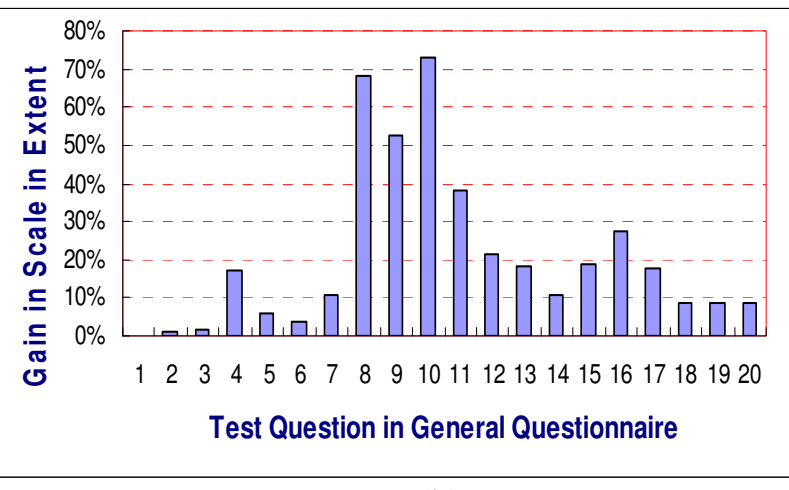

(b)

Fig. 13 Comparison between rates from Post- and Pre- Questionnaire (a), and Gain in Rates through Module Implementation (b) from one university $(\mathrm{N}=12)$ 
Comparison between rates from pre- and post- questionnaires and the gain in rates through implementation from one university $(\mathrm{N}=12)$ are shown in Fig.13a and Fig. 13b respectively. These results indicate that the large gains take place in following aspects:

1. Relating nanotechnology to civil engineering (72\% for Q10);

2. Knowledge of nanotechnology (68\% for Q8);

3. Learning about nanotechnology in curriculum (52\% for Q9);

4. Thinking that nanotechnology will impact civil engineering design and practice $(38 \%$ for Q11).

The notable gains are also obtained in students' knowledge about strategies of innovation and creativity (21\% for Q12), and in the extent to which students utilized the strategies of creativity for innovative design and creative activities (10\% for Q14). It is also notable that there is a $17 \%$ gain of in the interest at engineering research (for Q4) and a $10 \%$ gain in pursuing engineering research (for Q7). However, there is only 5.8\% gain in the willing to pursue graduate study for Master's degree (Q5), and 3.6\% gain in the willingness to pursue graduate study for Ph.D. degree (Q6). The rates in these two aspects before the course module implementation are only medium from pre-test. Thus, how to attract more students into graduate studies remains a challenge. In the future implementation, efforts need to be made for improvement in the above two these aspects. One way is to provide information on graduate assistantship, application process, graduate student life, and job opportunities and satisfaction with graduate degree and research careers. There is almost no gain in students' interest in engineering and pursuing an engineering career. This is because these students are junior and senior students who have committed to engineering, the rates in these two aspects were higher (over 4.0) before the course module implementation. This implicates that the efforts to increase interest in engineering and pursuing an engineering career should be made for younger students who may have not committed to engineering.

\section{Summary and Implications}

Nanotechnology education has to be integrated into current mainstream civil undergraduate engineering curriculum. The new course modules should emphasize how to utilize nanotechnology innovations to develop new diverse learning experience and enhance expected undergraduate engineering educational outcomes. The presented project is the first attempt to integrate nanotechnology into a main stream civil engineering curriculum. New course and lab modules have been developed and impacted the student learning experience.

The outcomes from the $1^{\text {st }}$ year implementation of the new course modules indicate that students are excited about learning new technology and interested at these new course modules, and think that these topics are more practical than interesting. Particularly, the course design project provided students with an unusual opportunity to explore their creativity potential. All students have presented innovations related to nanotechnology for civil infrastructures in their course design projects, and some students have developed their own innovative ideas. Students' interest in engineering research was also increased through the implementation of the new course modules; however, their desire for pursuing graduate studies in engineering is not increased proportionally. How to increase this desire still remains a challenge. Students suggested that more application examples are needed. The negative response from some students is that they 
have to learn too much in one course. The authors will add new application examples and consider the student course load through balancing the existing course contents and new modules. Meanwhile the strategies for motivating students to take more challenge and efforts in their studies will be explored.

\section{Acknowledgements}

The authors gratefully acknowledge the support of the Division of Engineering Education and Centers of the National Science Foundation under the grant EEC-0634279 (program manager Dr. Mary Poats). Any opinions, findings, conclusions, or recommendations expressed in this material are those of the authors and do not necessarily reflect the views of the National Science Foundation. We would like to thank Dr. Jin-song Pei, who provided the implementation results from the University of Oklahoma. We would also like to thank Dr. Jon Makar at Institute of Research for Construction in Canada and Mr. Tony Kojundic from the Silica Fume Association, as well as project external advisors, for their contribution and support to the project.

\section{Reference}

1. Kuennen, T., (2004). "Small Science Will Bring Big Changes to Roads," Better Roads Magazine, July, 2004

2. The Scottish Centre for Nanotechnology in Construction Materials, (2003). "1st International Symposium on Nanotechnology in Construction,"< http://www.allconferences.com/>, June, 2003, Paisley, Scotland, United Kingdom

3. The Centre for Nanomaterials Applications in Construction, (2005). "2nd International Symposium on Nanotechnology in Construction," <http://www.mmsconferencing.com/nanoc/>, November 2005, Euskalduna Palace Bilbao, Spain

4. Transportation Research Board, (2006). "Nanotechnologies Related to Concrete Construction," Basic Research and Emerging Technologies Related To Concrete Committee (AFN10), Emerging Technology for Design and Construction Committee (AFH30), 85th TRB Annual Meeting - January 22-26, $2006<$ http://trb.org/am/ip/assembly_detail.asp?id=5837\&e=68>

5. University of Florida, (2006). "NSF Workshop on Nanomodification of Cementitious Materials: Portland Cement Concrete and Asphalt Concrete," <http://www.ce.ufl.edu/nanoworkshop/>, Gainesville, Florida

6. Mann, S., (2006). "Nanotechnology and Construction," Institute of Nanotechnology, Nanoforum Report on Nanotechnology and Construction < http://www.nanoforum.org >

7. Roco, M.C., (2002). "Nanotechnology - A Frontier for Engineering Education," International Journal of Engineering Education, Vol. 18, No. 5, Special Issue on Nanotechnology

8. Saafi, M., (2006). "Nanotechnology-Based Devices for Quality Control and Durability Monitoring of Concrete Material," proceeding 85th TRB Annual Meeting - January 22-26, 2006

9. Sto Corp., (2005). "Introducing Lotusan ${ }^{\mathrm{TM}}$ - the ExteriorCoating With the Lotus-Effect@," Sto News for the Applicator Professional, $3^{\text {rd }}$ Quarter, $2005<$ http://www.stocorp.com/webfiles.nsf/htmlmedia >

10. White, S.R., Sottos, N.R., Geubelle, P.H., Moore, J.S., Kessler, M.R., Sriram, S.R., Brown, E.N., and Viswanathan S., (2001). "Autonomic healing of polymer composites," Nature. 409, 200, pp794-797

11. Vernet, C. (2004). "Ultra-Durable Concretes: Structure at the Micro- and Nanoscale," Bulletin of the Materials Research Society, May 2004

12. Juan, S., (2003). "How to Be Creative ", Odd News, Harper-Collins $<$ http://www.harpercollins.com.au/drstephenjuan>

13. Csikszentmihalyi, M., (1998). Creativity, HarperCollins

14. Winter, A., et al. (1997). Brain Workout, St. Martin's Press

15. Wakefield, D., (1998). Creating from the Spirit, Ballantine

16. Norchem, (2005). "Silica Fume," Norchem Concrete Products, Inc, <http://www.norchem.com>

17. Nycon, (2004). "PVA Structural Fibers," Nycon, Inc., < http://www.nycon.com/default.htm >

18. American Society for Testing and Materials, (2005). Standard Practice for Estimating Concrete Strength by the Maturity Method. ASTM C1074. ASTM, Philadelphia, PA. 
19. Maxim, (2005). "Data Logger, Temperature/Humidity Loggers, and Sensors", Maxim Integrated Products, Inc $<$ http://www.maxim-ic.com/products/ibutton/ibuttons/thermochron.cfm>

20. Dynalloy, "Flexinol ® Deluxe Kit," <http://www.dynalloy.com/kits.shtml>

21. Song, G., Qiao, P., Z., Binienda, W. K.; and Zou, G. P., (2002). "Active Vibration Damping of Composite Beam using Smart Sensors and Actuators," the Journal of Aerospace Engineering, Vol. 15, No. 3, July 1, 2002.

22. Shih, H.-R., Tzou, H.S., Saypuri, M., (2005). "Structural vibration control using spatially configured optoelectromechanical actuators," Journal of sound and Vibrations, February, 2005. 